\title{
Atypical Protein Kinase C
}

\section{Hyperactivity in Insulin-Resistant and Insulin-Sensitive Forms of Alzheimer's Disease: A Potential Therapeutic Target}

\author{
Robert V. Farese ${ }^{1,2} \bullet$ Mark A. Kindy ${ }^{1,3} \bullet$ Mini P. Sajan ${ }^{1,2}$ \\ ${ }^{1}$ James A. Haley Veterans Medical Center, Tampa, FL, USA; ${ }^{2}$ Department of Internal \\ Medicine, University of South Florida College of Medicine, Tampa, FL, USA; ${ }^{3}$ School of \\ Pharmacy, University of South Florida, Tampa, FL, USA
}

Author for correspondence: Robert V. Farese, James A. Haley Veterans Medical Center, 13000 Bruce B. Downs Blvd, Tampa, FL, USA. Email: rfarese@usf.edu

Doi: https://doi.org/10.36255/exonpublications.alzheimersdisease.2020.ch6

\begin{abstract}
Alzheimer's disease (AD) is commonly, not always, associated with insulin-resistant, hyperinsulinemic, and obesity/type-2-diabetic (O/T2D) states. Partial deficiencies of brain insulin receptor (IR) indeed occur in both O/T2D-AD and human $\mathrm{AD}$, but these deficiencies can be bypassed by hyperinsulinemia, which activates atypical protein kinase $\mathrm{C}(\mathrm{aPKC})$ and $\beta$-secretase, increases $\mathrm{A} \beta$-peptide and phospho-thr-231-tau levels, and induces memory impairments; importantly, these aberrations are reversed by reduction of liver/aPKC-dependent hyperinsulinemia or direct blockade of brain aPKC. New evidence shows that aPKC acts via nuclear factor kappa-B to increase $\beta$-secretase mRNA/protein levels in brain, where $\beta$-secretase acts on both $\beta$-amyloid precursor protein to increase $\mathrm{AD}$ risk and IR to limit beneficial (aPKC independent) insulin effects, particularly in normo/hypoinsulinemic $\mathrm{AD}$, and liver, where $\beta$-secretase acts on IR to initiate or abet development of insulin resistance and compensatory hyperinsulinemia
\end{abstract}

In: Alzheimer's Disease: Drug Discovery. Huang X (Editor). Exon Publications, Brisbane, Australia. ISBN: 978-0-6450017-0-9; Doi: https://doi.org/10.36255/exonpublications.alzheimersdisease.2020 Copyright: The Authors.

License: This open access article is licenced under Creative Commons Attribution-NonCommercial 4.0 International (CC BY-NC 4.0) https://creativecommons.org/licenses/by-nc/4.0/ 
that originates from diet-induced hepatic aPKC activation. Fortunately, agents that inhibit PKC- $\lambda / \mathrm{s}$ in brain, liver, or both effectively reduce $\beta$-secretase levels and adverse actions therein, and moreover, prevent/reverse O/T2D and AD development in mouse models. This chapter summarizes work implicating the critical role of atypical PKC in the development of liver-dependent hyperinsulinemia as a risk factor in $\mathrm{O} / \mathrm{T} 2 \mathrm{D}$-associated $\mathrm{AD}$ and $\beta$-secretase-mediated pathological alterations in brains of O/T2D-associated and O/T2D-independent AD.

Keywords: atypical protein kinase $C ; \beta$ amyloid precursor protein; $\beta$ secretase; insulin-resistant Alzheimer's disease; insulin-sensitive Alzheimer's disease

\section{INTRODUCTION}

In the United States, according to the Alzheimer Association, late onset (LO) Alzheimer's disease (AD) afflicts 1 in 5 women and 1 in 10 men over the age of 65, and $45 \%$ of people over the age of 85 . Hyperinsulinemic forms of obesity, the associated metabolic syndrome (MetS) and type 2 diabetes mellitus (T2DM), which together afflict half of all adults in the United States, are thought to increase LO-AD risk. The extent and consequences of these interrelated disorders are enormous, in terms of morbidity, mortality, and cost. Although pathogenetic mechanisms of AD are still unsettled, both early-onset, inherited forms of AD and sporadic LO-AD are thought to be dependent on pathological increases of $A \beta$-plaques that arise from $A \beta$-peptides, whose production is initiated by the aspartyl peptidase, $\beta$-site $\beta$-amyloid precursor protein ( $\beta$ APP) cleaving enzyme- 1 (BACE1), acting on specific amino acids of $\beta A P P(1-4)$. Indeed, BACE1 levels are increased in many or most, but not necessarily all, AD patients (5). In either case, BACE1 action is thought to be essential for the development of classical AD pathology, and this dependency spurred the widely heralded development of BACEl inhibitors for AD treatment. Unfortunately, however, in human clinical trials, BACEl inhibitors apparently produced cognitive/memory impairments, and this may reflect requirements for uncertain actions of BACEl in cognitive/ memory functions, or development of compensatory increases in BACE1containing vesicles (6) that may be dysfunctional owing to inhibitor binding, with impairment in vesicle trafficking needed for cognitive/memory functions.

As to whether BACEl is needed for normal cognition and memory, BACE1 knockout $(\mathrm{KO})$ does not produce significant aberrations in mice $(7,8)$, but it is uncertain if humans have greater dependence on BACEl. It is also uncertain if vesicle trafficking needed for memory function is disrupted by BACEl inhibitors. However, there is another approach that would avoid the use of BACEl inhibitors in $\mathrm{AD}$, that is, development of therapeutic measures to partially diminish BACEl content to levels that sufficiently reduce $A \beta$-peptide production while maintaining essential BACEl functions. In this regard, we recently found that the atypical protein kinase $\mathrm{C}(\mathrm{aPKC})$ signaling factor, $\mathrm{PKC}-\lambda / \mathrm{l}$, is critically needed for the production of BACEl mRNA and protein (presumably BACEl transcription), not only in the brain, where BACEl acts upon $\beta A P P$ to generate $A \beta$-peptides in AD, but also in liver, as discussed later in greater detail. BACEl diminishes insulin receptor (IR) levels (9) and thereby contributes to the development of hepatic and 
systemic insulin resistance that, in turn, as alluded to, leads to hyperinsulinemia, which we postulate, increases AD risk in states of obesity, MetS and T2DM. Moreover, we have developed chemical agents that, when administered to mice orally or parenterally (subcutaneously [SC] or intravenously [IV]), inhibit both liver and brain PKC- $\lambda / \mathrm{l}$, and thereby reduce BACEl levels in both organs; but, when given nasally, it inhibits brain, but not liver, PKC- $\lambda / \mathrm{t}$, and thereby reduce brain, but not liver, BACE1 levels. Furthermore, in very recent studies, we found that oral and nasal treatment of transgenic $(\mathrm{Tg}) \mathrm{AD}$ mice with an inhibitor of PKC- $\lambda / \iota$ over several months diminished brain aPKC activity and BACEl levels and, most importantly, largely prevented the development of AD pathology and memory impairment.

\section{THE ESSENTIAL ROLE OF BACE1 IN THE PATHOGENESIS OF AD}

It seems abundantly clear that the aspartyl protease, BACE1, acts upon $\beta A P P$ in the brain to initiate the production of $A \beta_{1-40 / 42}$ peptides that polymerize to form the characteristic A $\beta$-plaques of AD (1-4). Indeed, genetic KO of BACEl blocks $A \beta_{1-40 / 42}$ production and $A \beta$-plaque formation in Tg $A D$ mice carrying human mutations that increase susceptibility to actions of BACEl (e.g., $\mathrm{APP}_{\text {Swede }}$ ) and $\gamma$-secretase (e.g., presenilin-1 [PS1]) $(7,8)$. This BACE1-KO-induced protection against the development of $\mathrm{AD}$ pathology in $\mathrm{Tg} \mathrm{AD}$ mice is accompanied by the improvement of cognition/memory losses that occur in unprotected wild-type (WT) Tg AD mice, suggesting that (i) BACEl-dependent pathology is required and may account for cognitive/memory losses in $\mathrm{Tg} \mathrm{AD}$ mice (and presumably other AD states) and (ii) BACEl itself is not required for cognitive/memory functions, at least in mice. Moreover, delayed conditional KO of brain BACEl in $\mathrm{Tg} \mathrm{AD}$ mice, in which AD pathology and cognitive/memory losses are already well established, was found to reverse pathology and cognitive/memory losses therein (7), suggesting reversibility following BACEl depletion, at least in Tg mouse AD models.

Although elevations of brain BACE1 levels have been observed in some series of human AD patients (5), this is not always the case, and increases in BACE1dependent $A \beta$-peptide production may also be due to enhanced trafficking of

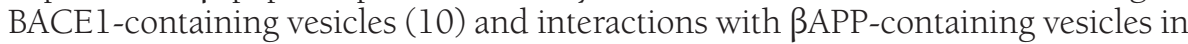
the Trans Golgi Network (TGN), where BACEl is activated by increases in intravesicular acidity and perhaps other factors, for example, increased phosphorylation of ser-498 in the cytosolic, C-terminal tail of BACEl. Also, changes in other factors, for example, mutations in $\beta A P P$, PS1, or $\gamma$ - or $\alpha$-secretase(s), or altered clearance of $A \beta$-peptides, may serve to increase A $\beta$-peptide levels. Regardless of the initial or later causes, BACEl action is critically needed for $A \beta$-peptide production and $A \beta$-plaque formation in $A D$, and $B A C E l$ is an attractive target for the treatment of $\mathrm{AD}$ and minimal cognitive impairment (MCI).

Unfortunately, as alluded to, the use of chemical agents that directly inhibit BACEl in humans with AD or MCI resulted in impairments in cognition/memory, despite apparent reduction of $A \beta$ production. This raises the possibility that increases in BACEl levels, activity and/or action, do not explain cognition/ 
memory losses in human AD/MCI, or losses of cognition/memory reflect a requirement for BACE1 itself, or there are direct or indirect untoward effects of BACE1 inhibitors. With respect to the latter possibility, as discussed, BACE1 levels increase with BACEl inhibitor treatment (6), and increases in vesicles containing chemically inhibited forms of BACEl may interfere with the vesicular trafficking needed for neurite formation, cognition, and memory induction. Whether decreases in BACEl levels that are elicited by inhibition of regulatory factors upstream of BACEl transcription, in particular for the present discussion, $\mathrm{PKC}-\lambda / \mathrm{s}$, or downstream factors linking PKC- $\lambda / \mathrm{s}$ to BACE1, will adversely affect cognition/memory is uncertain, but this approach seems worthy of consideration, given the present dearth of effective treatments for MCI and AD.

\section{SYSTEMIC VERSUS BRAIN INSULIN RESISTANCE IN DIABETES-ASSOCIATED AND NONDIABETIC AD}

LO-AD and the insulin-resistant states of T2DM and its forerunners, that is, obesity and MetS, have frequently been found to coexist, for example, in a particularly important study, $80 \%$ of all AD patients seen at the Mayo Clinic were found to have, in half the cases, overt T2DM (fasting blood sugar [FBS] over $125 \mathrm{mg} / \mathrm{dL}$ ) or, in the other half, pre-T2DM (FBS 110-125 mg/dL) (11). In view of this and other reports, it has been speculated that the systemic insulin resistance, which is generally, if not usually, seen in T2DM, pre-T2DM, obesity, and the MetS, serves as a risk factor for LO-AD. It has further been speculated or tacitly assumed that, as in peripheral tissues, most notably, muscle, where resistance to insulin is particularly severe, the brain is similarly insulin resistant, that is, essentially unresponsive to insulin, and therefore hypoinsulinized in the aforesaid insulin-resistant states. Accordingly, it is proposed that this hypoinsulinization as such provides an explanation for increases in AD risk in states of systemic insulin resistance.

In keeping with the idea that insulin action in brain is reduced in AD, brain IR activity and/or number is reportedly mild-moderately reduced in the brains of humans with nondiabetic AD (12); accordingly, the concept of brain hypoinsulinization has been reemphasized and expanded, and it has been proposed that the brain itself is insulin resistant and, moreover, hypoinsulinized, in both nondiabetic AD and obesity/MetS/T2DM-associated AD.

However, in view of our more recent findings, as discussed later, this proposal appears to be overstated and in need of modification. Thus, it is indeed reasonable to postulate that deficiencies of the brain IR would of necessity impair insulin effects in the brains of AD patients that have normal or low circulating levels of blood/plasma insulin, as in non-diabetic, normo-insulinemic AD, or in late forms of T2D, if and when insulin levels fully diminish to normal or subnormal levels. On the other hand, the same cannot be said in conditions of hyperinsulinemia, wherein elevated levels of blood insulin can bypass partial defects in the IR in many or most tissues by using "spare" IRs, that is, IRs in excess of those needed to produce maximal downstream effects.

In this respect, note that a more severe insulin resistance that exists in T2D muscle is largely a result of down-regulation of IRS-1 and its ability to activate phosphatidylinositol (PI) 3-kinase (3K), which is needed to produce 
PI-3,4,5-( $\left.\mathrm{PO}_{4}\right)_{3}\left(\mathrm{PIP}_{3}\right)$, which activates signaling factors required for insulinstimulated glucose transport in muscle, that is, Akt and aPKC. Also note that this defect in muscle IRS-1/PI3K is a "post-IR" impairment that cannot be bypassed by hyperinsulinemia and should not be confused with IR defects that can be bypassed via "spare" IRs, which, as will become evident in this chapter, are present and operative in both liver and brain (13-17).

And, in marked contrast to muscle, insulin action in liver and activation of hepatic Akt and aPKC in obesity, the MetS and early T2DM are excessive in many respects owing to hyperinsulin-emia-induced activation of "spare" hepatic IRs. Indeed, note that, unlike the post-IR defect in muscle IRS-1/PI3K which occurs early in high-fat-fed (HFF) mice (18), the post-IR impairments of hepatic IRS-1/PI3K and subsequent Akt activation by insulin occur only later as T2DM progresses, that is, only after 2-3 months of high-fat feeding in the classical mouse model of dietdependent obesity/MetS/T2DM (15). Also note that the activation of hepatic IRS-2/ PI3K and subsequent aPKC activation by insulin remains intact even in late T2DM when IRS-1/PI3K/Akt activation is impaired: in short, hepatic aPKC remains activated by hyperinsulinemia and continues to promote increases in hepatic production of glucose and lipids throughout the course of obesity, the MetS and T2DM. Moreover, as stated, the post-IR defect in muscle described earlier occurs very early in initial stages of the development of diet-induced obesity/MetS/T2DM in HFF mice (18), viz, and several months before impairments in hepatic IRS-1/PI3K and Akt develop. And this muscle defect in glucose metabolism undoubtedly contributes importantly to early elevations of blood insulin to levels (18) that are sufficient to bypass IR defects and strongly/maximally activate key processes in other tissues, most notably for the present discussion, liver and brain. In keeping with mouse studies, note that defective glucose transport in muscle occurs early in human obesity, well before the development of pre-T2D and overt T2DM.

\section{INSULIN RECEPTOR DOWNREGULATION IN OBESITY/T2DM}

\section{AND AD}

The downregulation of the brain IR that is seen in nondiabetic AD (12) and diabetes-associated $\mathrm{AD}$ (see below) may well be at least partly due to increases in BACE1-dependent degradation of the IR, as this mechanism has recently been shown to clearly be operative in the liver in various murine and human forms of obesity and T2DM (9). Indeed, in initial studies, we too have found that there are decreases of IR levels in both brain and livers of hyperinsulinemic, HFF, and obese/MetS/T2DM mice, and these decreases in IR levels in both brain and liver are associated with, and apparently dependent on, increases in PKC- $\lambda / \mathrm{L}$ activity and aPKC-dependent increases in BACEl levels and proteolytic activity, as aberrant elevations in BACEl levels and subsequent deficiencies in IR levels are abrogated by the inhibition of aPKC.

In addition to the above-described aPKC/BACEl-dependent degradative mechanism for the decreases in IR levels, the activity of the IR may also be diminished by inhibitory phosphorylation of the IR that is provoked via negative feedback mechanisms that occur during actions of a wide variety of factors, many of which are likely to be increased and operative in damaged AD tissues. 
These factors include lipids, such as ceramide and phosphatidic acid (PA), both of which directly activate aPKCs; cellular stress, inflammatory, and oxidative factors that activate phospholipases C and D (PLC and PLD) that produce diacylglycerol (DAG) and $P A$, respectively (note that DAG and PA can interconvert); DAG-sensitive conventional (c) and novel (n) PKCs $(\alpha, \beta, \gamma, \delta, \varepsilon, \theta)$ that phosphorylate and diminish activity of the IR and/or IRS- 1 which activates PI3K. Also note that negative feedback on the IR and IRS-1 can be mediated by phosphorylation provoked by a variety of signaling factors, including Akt, aPKC, mammalian target of rapamycin (mTOR), and ERK, all of which are activated by insulin and various polypeptides that operate via PI3K. In this regard, note that aPKC, and Akt and ERK are all reportedly hyperactivated in brains of humans with nondiabetic AD (12), and any of these downstream factors may negatively feedback on the IR.

Finally, note that the partial resistance at the IR level in nondiabetic AD brain is in fact readily overcome by elevated insulin levels (12), which may be acting via "spare" IRs, that is, present in excess of that needed for maximal activation of downstream factors; alternatively or additionally, IGF-1 receptors may also be activated by elevated insulin levels and may contribute to the activation of IRS-1/ PI3K, Akt, and aPKC. And, in this regard, note that, despite decreases in IR number that we recently observed in brains of obese/MetS/T2D HFF mice, the IR is nevertheless maximally activated by hyperinsulinemia in HFF mice (13), apparently by the activation of "spare" IRs. Further note that the treatment of HFF mice with inhibitors of brain aPKC (discussed later) diminished brain BACE levels and simultaneously increased brain IR levels.

\section{HYPERINSULINEMIA IN INSULIN-RESISTANT FORMS OF OBESITY AND T2DM AS A RISK FACTOR FOR AD}

With the prevailing assumption that the brain itself is insulin resistant and more importantly hypo-insulinized in AD, we were surprised to find (14), in whole brain and individual neurons of the anterior cortex and hippocampus of systemically insulinresistant, hyperinsulinemic HFF mice, ob/ob mice, and, very importantly, monkeys with long-standing, diet-dependent obesity/T2D, that insulin signaling to both Akt and $\mathrm{aPKC}$, and to all examined Akt substrates, viz, glycogen synthase kinase-2 $\beta$, mTOR, and forkhead homeobox factors (FoxOl, FoxO3a, and FoxO4), is uniformly increased (Figure 1). Indeed, increased Akt/aPKC signaling in obese/T2D HFF and ob/ob mice appears to be maximal, as insulin treatment (which rapidly, over $15 \mathrm{~min}$, maximally increases brain Akt and aPKC activities in normal mice) did not elicit further increases in these activities in hyperinsulinemic HFF and ob/ob mice (13, 14).

As alluded to, we moreover found that the brain IR itself, despite a reduction in total levels, is nevertheless maximally activated (as per total phosphotyrosine content of the IR- $\beta$ subunit) by the hyperinsulinemia that exists in HFF obese/ T2D mice (13). It therefore seems clear that any IR deficiency that is present in the brains of HFF obese/T2D mice is readily bypassed by the activation of "spare" IRs by hyperinsulinemia in HFF mice (13).

Finally, note that the hyperinsulinemia as such in insulin-resistant mice appears to be largely/fully responsible for increases in brain IR and Akt and aPKC signaling, as 


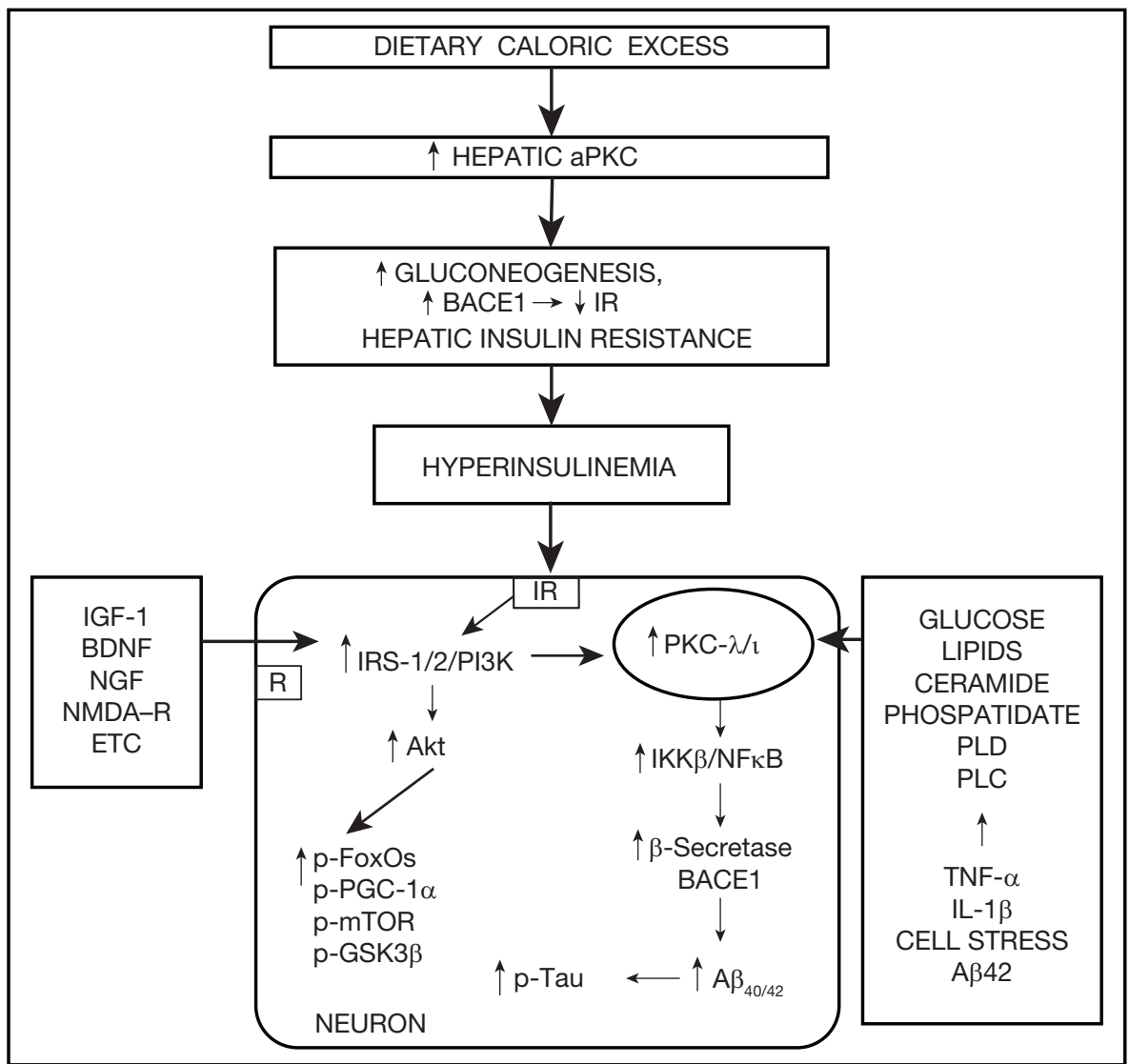

Figure 1. Atypical PKC (aPKC)-dependent risk factors in Alzheimer's disease.

Activity of neuronal aPKC (encircled) can be excessively activated by (i) diet/liver/aPKCdependent hyperinsulinemia acting on insulin receptors (IRs) and IR substrates (IRS-1/2), (ii) other factors (left box) acting on noninsulin receptors $(R)$ that similarly activate phosphatidylinositol 3-kinase (PI3K) by IRS-1/2 and/or other factors, and (iii) various agents and metabolites (right box) that operate directly or indirectly via phospholipases $\mathrm{D}$ and $\mathrm{C}$ to increase levels of ceramide and phosphatidic acid, which directly activate aPKC. In turn, aPKC acts via inhibitor of kappa-B kinase-beta (IKKß) to increase the activity of nuclear factor kappa-beta $\left(N F_{K} B\right)$, which acts directly to increase $\beta$-secretase (aka, BACE1) transcription, and thus increase levels of $A \beta$-peptides and phospho-tau, that is, precursors of Alzheimer plaques and tangles. Note that, although not shown, NFKB also increases transcription and levels of proinflammatory cytokines, tumor necrosis factor-alpha (TNF- $\alpha$ ) and interleukin 1- $\beta$ (IL-1 $\beta)$, and perhaps other cellular stress/oxidant/inflammatory factors, which, along with increases in A $\beta 42$ peptides, act, as depicted (right box), to increase aPKC activity, perhaps creating multiple vicious cycles.

the correction of hyperinsulinemia (elicited by improvement in hepatic abnormalities following treatment with aPKC inhibitor, aurothiomalate [ATM] (14), in doses that selectively act in liver [but not in brain] to fully ameliorate obesity/MetS/T2DM and correct hyperinsulinemia (16)) was attended by (i) return of all brain insulin signaling aberrations, including increases in activities of Akt, Akt substrate, and aPKC, to their normal resting/basal levels and (ii) restored ability of insulin to acutely and fully activate both Akt and aPKC in the brain (14). Obviously, unlike aPKC inhibitors 
1H-imidazole-4-carboxamide, 5-amino-1-[2,3-dihydroxy-4-[(phosphono-oxy) methyl]cyclopentyl-[1R-(1a,2b,3b,4a)] (ICAPP), 1H-imidazole-4-carboxamide, 5-amino-1-[2,3-dihydroxy-4-[(hydroxyl)methyl]cyclopentyl-[1R-(1a,2b, 3b,4a)] (ICAP), and 2-acetyl-cyclopentane-1,3-diketone (ACPD) (see later), ATM did not cross the blood-brain barrier (BBB) in these studies.

Accordingly, as depicted in Figure 1, we postulate that persistent hyperactivation of brain Akt in insulin-resistant states and phosphorylation/inhibition of activities of all brain FoxOs (1/3a/4/6) and PGC-1 $\alpha$ (14) may be problematic over time, as their transcriptional actions are needed to maintain cognitive functions and neuronal integrity (see discussion in (14)). On the other hand, Akt may also have more acute beneficial effects on memory and overall brain metabolism and may also function as an antiapoptotic agent. In any case, the hyperactivation of brain $\mathrm{aPKC}$, and subsequent increases in BACE1, $A \beta_{1-40 / 42}$, and phospho-tau ( $\mathrm{p}$-tau) $(13,14)$ most likely have detrimental effects.

To summarize, systemic insulin resistance that originates in the liver due to diet-dependent caloric excess (15) or in the brain appetite/energy center as in leptin-deficient ob/ob mice (17), or in muscle that is defective in glucose transport (16) is accompanied by key abnormalities in liver that includes the hyperactivation of hepatic aPKC, aPKC-dependent increases in gluconeogenesis and lipogenesis, and development of hyperinsulinemia. In turn, hyperinsulinemia leads to chronic hyperinsulinization of the brain, which, by hyper-activating brain aPKC, increases levels of the factors that produce pathological plaques and tangles in $\mathrm{AD}$, that is, BACEl expression, BACEl activity, and BACEl-dependent increases in $A \beta$-peptides and p-tau. Obviously, this hypothesis is at odds with postulates that the brain itself is uniformly insulin resistant, unresponsive to insulin, and hypoinsulinized in hyperinsulinemic states of obesity. MetS and T2DM, and brain insulin resistance per se increase AD pathology in these states (19-22). In any case, liver involvement plays a critical role in causing systemic insulin resistance, and liver abnormalities are dependent on excessive activation of hepatic aPKC (15-18). This dependence on hepatic aPKC explains how treatment with inhibitors of hepatic aPKC and correction of hyperinsulinemia can reduce brain aPKC activity and thereby improve BACE1, $A \beta_{1-40 / 42}$, p-tau, and memory alterations $(13,14)$.

On the other hand, in AD that is not associated with hyperinsulinemia, for example, in lean nondiabetic subjects, there may well be an impairment in brain IR activity or a deficiency of brain IR, which limits insulin action in the brain, that is, in response to normal or low blood insulin levels. As discussed, this, of course, may occur in nondiabetic, normo-insulinemic $\mathrm{AD}$ and possibly in later stages of T2D-related AD if and when insulin levels are reduced to normal or subnormal levels. These differences in ambient insulin levels may explain how some, but not all, studies suggest that nasal insulin treatment, as well as subsequent brain insulinization, has beneficial effects in AD (19-22).

\section{EFFECTS OF DAG-SENSITIVE PKCs $(\alpha, \delta, \varepsilon)$ VERSUS aPKC- $\lambda / \iota$ ON BACE1 AND AD}

In addition to PIP $_{3}$-activated aPKCs, DAG-activated conventional (c) cPKCs and novel (n) nPKCs can influence AD pathology in a variety of ways. For example, 
the activations of both DAG-sensitive $c P K C-\alpha$ and $n P K C-\varepsilon$ diminish the amyloidogenic pathway and limit $A \beta_{1-40 / 42}$ production by activating $\alpha$-secretase, which cleaves $\beta$ APP between sites cleaved by $\beta$-secretase and $\gamma$-secretase, thus producing shortened, nonamyloidogenic peptides $(1,2,23,24)$. In this regard, note that insulin activates all DAG-sensitive PKCs in muscle, liver, and adipose tissues, but whether this occurs in brain is uncertain and is in need of study.

Additionally, the activation of $\mathrm{PKC}-\alpha$ may diminish $\mathrm{A} \beta_{1-40 / 42}$ production indirectly by restraining PKC- $\varepsilon$-dependent $\beta A P P$ expression, as it has been reported that phorbol-ester-induced deficiency of PKC- $\alpha$ is accompanied by increases in PKC- $\varepsilon$, $\beta$ APP expression, $\beta A P P$ accumulation in the TGN, and subsequent increases in BACEl-dependent $A \beta_{1-40 / 42}$ production (25).

On the other hand, some LO-AD patients have gain-of-function mutations in PKC- $\alpha$ that diminishes cognitive/memory functions by altering synaptic activity (26). However, in the absence of this mutation, it is unknown if there are similar memory problems that result from PKC- $\alpha$ activation arising from (i) de novo synthesis of PA/DAG owing to increases in glucose and/or fatty acids, (ii) PLCproduced DAG, or (iii) increases in levels of blood insulin, which activates all c/nPKCs, including PKC- $\alpha$, by a variety of mechanisms in muscle, liver, and adipose tissues (information on brain c/nPKCs during insulin action is lacking).

In marked contrast to the potentially beneficial effects on $\mathrm{AD}$ conferred by the activation of DAG-sensitive aPKC- $\alpha$ and $\mathrm{nPKC}-\varepsilon$ and subsequent activation of $\alpha$-secretase, the effects of the DAG-sensitive nPKC, PKC- $\delta$, are much different, in that PKC- $\delta$ overexpression increases, and PKC- $\delta$ knockdown decreases, BACEl levels and $A \beta_{1-40 / 42}$ production in neuronal cells (27). Further, like the increases in activity or levels of PKC- $\lambda / \mathrm{L}$ in brains of humans with AD (12), PKC- $\delta$ levels are increased and correlate with increases in BACEl levels in brains of AD humans (27).

And, very interestingly, inhibition of PKC- $\delta$ by rottlerin simultaneously protects $\mathrm{Tg} / \mathrm{APP} / \mathrm{PS} 1 / \mathrm{AD}$ mice from developing increases in BACEl and A $\beta$-peptide/plaque production, and aberrations in cognition/memory functions (27). However, note that, like PKC- $\lambda / \mathrm{l}$, which activates NFKB in liver $(15-17,28)$ and at least certain other tissues, for example, lymphocytes (29) (and presumably in brain, as discussed further later), PKC- $\delta$ similarly activates brain/neuronal NFkB (27), which, in turn, increases the expression of proinflammatory cytokines, TNF- $\alpha$, and IL-1 $\beta$, which, in turn, activate NFKB by a PKC- $\lambda / \imath$-dependent mechanism (30). And, as PKC- $\delta$ is also activated by NFKB (27), this suggests operation of a vicious cycle and raises the possibility that the activation of PKC- $\lambda / \mathrm{s}$ by TNF- $\alpha$ and IL- $1 \beta$ may explain or contribute to BACEl increases and AD-abetting effects of PKC- $\delta$ overexpression (see Figure 2).

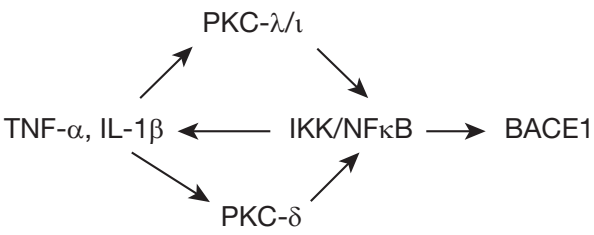

Figure 2. Potential interplay of aPKC, PKC- $\lambda / \mathrm{\iota}, \mathrm{nPKC}$, and PKC- $\delta$, to operate upstream and downstream of IKK $\beta / N F K B$ and act cooperatively in a vicious cycle to increase BACE1 transcription. 
Also note that, in the previously cited PKC- $\delta$ study (27), BACEl mRNA and protein levels were substantially increased in Tg/APP/PS1/AD mice, and inhibition of PKC- $\delta$ activity by rottlerin reduced BACEl levels back to normal levels in Tg/ APP/PS1 mice, but had little or no effect on basal BACEl levels in WT cells. This partial reduction of elevated BACEl levels to normal in Tg AD mice contrasts with the marked (up to 80-90\%) reductions of basal/resting levels of BACE1 protein and mRNA seen in both brain and liver of mice following chemical inhibition or haploinsufficiency of PKC- $\lambda$. Thus, PKC- $\lambda$ may be more potent than PKC- $\delta$ in regulating BACE1 transcription.

In this regard, further note that, in adipocytes, PKC- $\lambda$ and PKC- $\delta$ were found to physically interact, and the PKC- $\delta$ inhibitor, used in the aforesaid study (27), rottlerin, was found in another study (31) to block insulin-stimulated translocation of Glut4-containing vesicles to the plasma membrane independently of PKC- $\delta$, which, in fact, is not required for this process in adipocytes (31). Thus, rottlerin may have also inhibited PKC- $\lambda$, which is clearly required for Glut4 translocation in adipocytes (31). Or, stated differently, rottlerin is not a specific inhibitor of PKC- $\delta$, and the ability of rottlerin to improve AD pathology in Tg/APP/PSI/AD mice may reflect inhibition of PKC- $\lambda$ (or other factors that operate via NFKB), rather than $\mathrm{PKC}-\delta$. Alternatively, both $\mathrm{PKC}-\lambda$ and $\mathrm{PKC}-\delta$ may work together, cooperatively or additively, to regulate BACEl expression.

Finally, note that we have found that PKC- $\lambda / \mathrm{s}$ activity is increased in brains of APP/PS1/AD mice, and inhibition of PKC- $\lambda / \mathrm{s}$ with a relatively specific inhibitor, which clearly does not inhibit $\mathrm{PKC}-\delta$, is effective in improving memory impairments and for reducing $A \beta$-peptide and $A \beta$-plaque levels. This, of course, suggests that $\mathrm{PKC}-\lambda / \mathrm{s}$ is required for BACEl-dependent AD development in $\mathrm{Tg}$ $\mathrm{AD}$ mice, and AD-promoting effects of PKC- $\delta$ overexpression could conceivably involve PKC- $\lambda / \mathrm{s}$ activation by the above-described circular pathway.

Nevertheless, as alluded to, it is possible that both PKC- $\delta$ and PKC- $\lambda / \mathrm{t}$ are activated in the AD process, and, moreover, both may participate in the activation of NFkB, which, in turn, via TNF- $\alpha$ and IL- $1 \beta$, may further activate both PKC- $\delta$ (32) and PKC- $\lambda / \mathrm{s}$ (30) in the aforesaid circular "vicious" cycle. This possibility becomes even more interesting in light of the observation that increases in the activity of both PKC- $\delta$ and $\mathrm{PKC}-\lambda / \mathrm{l} / \zeta$, but not PKC- $\alpha$, are seen in T-lymphocytes isolated from AD humans, but only when stimulated ex vivo with $A \beta_{1-42}(33,34)$; this suggests that neurotoxic $A \beta_{1-42}(A \beta 42)$ activates both PKC- $\delta$ and PKC- $\lambda / \mathrm{s} / \zeta$, and this brings into play an interaction between the proliferative actions of PKC- $\lambda / \mathrm{t}$ and the proapoptotic effects of PKC- $\delta$, a combination that, when more fully activated, may enhance and hasten AD pathology development. The latter possibility, featuring a triad of increases in PKC- $\lambda / \mathrm{s}, \mathrm{PKC}-\delta$, and $\mathrm{NF} \kappa \mathrm{B}$ that are put into high-gear when $A \beta 42$ levels reach a threshold may provide an explanation for the rapid downhill phase of AD that follows a slow inductive process.

\section{aPKC INHIBITORS}

By high throughput screening, a number of compounds have been identified, which target a site at or near the substrate and/or the ATP-binding site of aPKCs, and potently inhibit both recombinant aPKCs and aPKC activity of cultured 
neurons and hepatocytes, but not myocytes. Among others yet to be studied, three such agents have been studied in detail: (i) ICAPP, which potently inhibits both recombinant PKC- $\lambda / \mathrm{L}$, and neuronal and hepatocyte PKC- $\lambda / \mathrm{t}$ (IC50, 1-10 $\mathrm{nM}$ ); (ii) ICAP, which is converted to active phosphorylated ICAPP intracellularly by adenosine kinase and is similarly potent for $\mathrm{PKC}-\mathrm{l} / \mathrm{\lambda}$ in neurons and hepatocytes ( $\mathrm{IC}_{50}, 10-100 \mathrm{nM}$ ); and (iii) ACPD, which comparably inhibits recombinant forms of both PKC- $\lambda / \mathrm{L}$ and $\mathrm{PKC}-\zeta$, and their activities in isolated neurons and hepatocytes $\left(\mathrm{IC}_{50}, 10-30 \mathrm{nM}\right)(15-17,28,35)$. Note that, whereas ACPD inhibits PKC- $\lambda / \mathrm{s}$ and PKC- $\zeta$ with equal potency, ICAPP and ICAP preferentially inhibit $\mathrm{PKC}-\lambda / \mathrm{l}$. Also note that the full-length, $70 \mathrm{kDa}$ aPKC in brain, is largely if not entirely PKC- $\lambda / \mathrm{L}$, as, unlike peripheral non-CNS PKC- $\zeta$, brain PKC- $\zeta$ lacks an inhibitory regulatory domain and exists largely as a shortened, $50 \mathrm{kDa}$, constitutively-active moiety, called PKM $\zeta$, which is particularly important in longterm memory (LTM) functions, as discussed later. Further note that ICAPP, ICAP, and ACPD do not inhibit recombinant forms of conventional/novel $(\mathrm{c} / \mathrm{n})$ PKCs $(\alpha, \beta, \delta, \varepsilon, \theta)(15-17,28,35)$.

During in vivo usage, in doses that are sufficient to effectively inhibit hepatic aPKC and largely, albeit not completely, reverse post-IR hepatic aberrations seen in mouse obesity/MetS/T2D models (15-17), the aforesaid inhibitors, ICAPP, ICAP, and ACPD, do not inhibit muscle, adipocyte, or brain aPKC, and, in all tissues, they have no inhibitory effects on Akt, or on AMPK. These inhibitors also have no effect on activities of an array of 35 other kinases independently tested by Life Technology Selectscreen Profiling, Madison, WI (15-17, 28, 34). We therefore believe that these agents have reasonable selectivity for aPKC, but as with all drugs, exclusive targeting cannot be assumed.

On the other hand, we have verified that partial heterozygous $\mathrm{KO}$ of total body PKC- $\lambda$ in the mouse (total homozygous KO is embryonic lethal), and thus haploinsufficiency of PKC- $\lambda$, has biological effects similar if not identical to those of the aforesaid chemical aPKC inhibitors in liver (36) and in brain: for example, PKC- $\lambda$ haploinsufficiency (i) in liver blocks all hepatic diabetic aberrations induced by high-fat-feeding (36) and (ii) in brain markedly diminishes BACEl levels and insulin-stimulated production of $\mathrm{A} \beta$-peptides. In addition, liver-specific $\mathrm{KO}$ of PKC- $\lambda$ (by administration of adenovirus encoding Cre-recombinase to PKC- $\lambda$-floxed mice) or liver-specific inhibition of hepatic aPKC by adenovirusmediated expression of kinase-inactive aPKC has biological effects in liver similar if not identical to those of the aforesaid chemical aPKC inhibitors on obesity/ MetS/T2DM $(18,36,37)$. We therefore are confidant that aPKC inhibition underlies all biological effects of ICAPP, ICAP, and ACPD that we have reported in both liver and brain.

However, at higher in vivo doses, ICAPP, ICAP, and ACPD inhibit brain, as well as liver, aPKC (13). Thus, in insulin-resistant, hyperinsulinemic states, these agents can reduce brain aPKC activity (i) at lower doses, indirectly via inhibition of liver aPKC and reduction of blood insulin levels, and (ii) at higher doses, by directly inhibiting brain aPKC. In this regard, note that, in published (38) and other pharmacokinetic/pharmacodynamic (PK/PD) studies, it was found that ICAP preferentially distributes to liver, but clearly passes the BBB to enter the brain. And, as found in other studies, ICAP is effective in liver and brain when given insufficiently increased doses by oral gavage (i.e., per os [PO]), as well when administered IV or SC. Moreover, when administered to mice intranasally, ICAP 
inhibits brain, but not liver, aPKC, suggesting that ICAP reaches the brain through neurovascular bundles that traverse the sphenoid sinuses and the cribriform plate; this raises the possibility that nasally administered aPKC inhibitors (or other agents) may be used to selectively target brain aPKC during AD treatment.

Furthermore, in cultured human neuronal cells and/or mouse hippocampal slices, ICAPP fully inhibits insulin-stimulated increases in activities of $70 \mathrm{kDa}$ PKC- $1 / \lambda$ and BACE 1 , and increases in the production of $A \beta_{1-40 / 42}$ by approximately $50 \%$ at $10 \mathrm{nM}$ and $90-100 \%$ at $100 \mathrm{nM}$, without inhibiting the putative memory protein, that is, constituently-active $50 \mathrm{kDa} P K M \zeta$ (13), which was alluded to earlier and discussed more fully later. And, in cultured human neuronal cells, ICAPP, at low $10 \mathrm{nM}$ concentrations, fully blocked 2-3-fold increases in BACE1 levels that were provoked by $24-\mathrm{h}$ insulin treatment. It therefore seems clear that prolonged treatment with high-dose insulin acts directly via aPKC to induce remarkably strong increases in neuronal BACEl levels. This bolsters our contention that hyperinsulinemia is an important risk factor for AD. It also seems very clear that aPKC inhibitors are working directly in neurons to alter BACEl and BACEldependent alterations in $A \beta$-peptide production.

\section{APKC REQUIREMENTS FOR MEMORY FUNCTION}

As alluded to, a number of findings suggest that the $50 \mathrm{kDa}$, constitutively active, brain-specific form of PKC- $\zeta$, that is, $\mathrm{PKM} \zeta$ (described earlier), functions in longterm potentiation (LTP) and LTM formation $(39,40)$. However, although PKM $\zeta$ $\mathrm{KO}$ in brain does not impair LTP/LTM, this appears to be explained by a compensatory increase in PKC- $\lambda / \mathrm{L}$ in PKM -null mice, as suggested by the fact that LTP/LTM is impaired by selective inhibition of PKC-1/ $\lambda$ by ICAP in PKM $\zeta$-null mice, but not in normal mice, wherein ICAP does not inhibit PKM (40). And, from the lack of effect of ICAP on LTP and memory function in normal mice (40), it may be argued that PKC- $\lambda / \mathrm{L}$ is not required for on-going LTP/LTM.

Indeed, in HFF mice, as reported in (13), aPKC inhibitor ACPD improved high-fat-diet-induced decreases in acute memory function (as per Novel Object Recognition $[\mathrm{NOR}]$ ) while blocking insulin-stimulated increases in $\mathrm{PKC}-\mathrm{l} / \mathrm{\lambda}$ activity, but largely sparing basal PKC-1/ $\lambda$ activity. Moreover, in other studies, a $50 \%$ loss of brain PKC- $\lambda$ in PKC- $\lambda$ haplo-insufficient mice, and subsequent decreases in PKC- $\lambda$ activity and BACE levels (80-90\%) did not impair training and memory functions in Radial Arm Water Maze (RAWM) and NOR tests. It thus appears that brain aPKC activity can be partially diminished to levels that markedly reduce $\mathrm{AD}$ development, without impairing memory processes.

Nevertheless, it should be noted that, whereas a marked and chronic loss of PKC-1/ $\lambda$ in a long-term, hippocampus/anterior-cortex-selective $\mathrm{KO}$ study showed essentially normal memory function and LTM/LTP, which was attributed to PKM compensation, acute KO of hippocampal/anterior-cortical PKC- $\lambda$ (and thus lacking time for compensatory changes) suggested a need for PKC- $\lambda$, in learning/memory processes, but only in more difficult (nonstandard) learning tasks (41). Furthermore, acute 1-month knockdown of $\mathrm{PKC}-\lambda$ produced specifically in the hippocampus by stereotactic injection of virus encoding shRNA, suggested that hippocampal PKC- $\lambda$ is needed for the initiation of LTP, short-term memory (as per contextual and trace 
fear testing), and consolidation of LTM (42). Thus, these inhibitory effects on learning and memory may be exaggerated by acute, and thus uncompensated, and excessive losses of PKC- $\lambda$, since (i) as discussed, partial inhibition of PKC- $\lambda / \mathrm{L}$ and simple reduction of elevated brain PKC- $\lambda$ activity to normal by aPKC inhibitor treatment improve memory loss (in NOR) in hyperinsulinemic HFF mice (13) and (ii) chronic $50 \%$ loss of PKC- $\lambda$ in PKC- $\lambda$-haploinsufficient mice did not impair learning/memory performance in RAWM and NOR tests.

It is, of course, interesting that brain PKC- $\lambda / \mathrm{t}$ and $\mathrm{PKM} \zeta$ (and perhaps other PKCs) can apparently compensate for losses of each other over time in the adult mouse brain, and these compensatory changes can satisfactorily maintain relatively normal memory functions. In any case, these caveats of aPKC inhibition or deficiency need to be kept in mind.

\section{aPKC ACTIVATORS}

Atypical PKCs are activated not only by insulin and other polypertides (IGF-1, NGF, BDNF, NMDA-receptor activators (43-47)) that activate PI3K and thereby produce PI-3.4.5-( $\left(\mathrm{PO}_{4}\right)_{3}\left(\mathrm{PIP}_{3}\right)$ which directly activates aPKCs (48) but also by C:14 and C:16 ceramides which directly activate aPKCs (15) (higher C:20-24 ceramides may be inhibitory); PLD-derived phosphatidic acid (PA), which, like $\mathrm{PIP}_{3}$, contains an acidic head group and directly activates aPKCs $(49,50)$; various factors, such as A $\beta 42(33,34)$ and certain oxidants (e.g., sorbitol $(49))$ and inflammatory factors (e.g., lipopolysaccharide (51)) which presumably activate PLCs and/or PLD to produce PA. Note that many of these metabolites and agonists are thought to abet AD development.

\section{CONTROL OF BACE1 TRANSCRIPTION BY NFKB}

There is clear evidence that NFKB is a strong, if not the major, transactivator of the BACEl gene in mouse brain (52-54). This is of considerable interest, as we have shown, that hyperinsulinemia in various O/MetS/T2D states (e.g., HFF, ob/ob, and HetM $\lambda$ KO mice $(15-18,36,37)$ and T2D humans $(28))$ leads to, in liver, aPKCdependent increases in (i) phosphorylation/activation of inhibitor of kappa-B kinase- $\beta$ (IKK- $\beta$ ), (ii) phosphorylation and thus dissociation of the inhibitor of NFKB inhibitor (IкB) from NFKB (and, presumably, subsequent degradation of IкB), (iii) transfer of the active p65/RelA subunit of NFKB into the nucleus, (iv) p65/RelA phosphorylation and activation, as per electrophoretic mobility shift assay, and (v) NFKB-dependent transcription of genes encoding various proinflammatory cytokines, including TNF- $\alpha$ and IL-1 $\beta$, that is, with increases in their mRNA and protein levels. These changes are clearly provoked by an aPKC-dependent mechanism, as shown by inhibition of aPKC by chemical inhibitors and expression of kinaseinactive-aPKC, and by various PKC- $\lambda$ KO methods.

In particular, note, in normal WT mice, acute insulin treatment over $15 \mathrm{~min}$ increases nuclear levels of the p65/RelA subunit of NFkB, and simple feedinginduced increases in insulin provoke increases in mRNA levels of TNF- $\alpha$ and 
IL-1 $\beta$; and all effects of insulin and feeding are blocked or markedly diminished in littermate mice haploinsufficient for PKC- $\lambda$ (35). And, perhaps most importantly, we found in both hepatocytes harvested from humans with long-term preexisting T2DM, and following acute 4-h insulin treatment of normal human hepatocytes, that there were increases in TNF- $\alpha$ and IL-1 $\beta$ mRNA levels by an aPKC-dependent mechanism (28). Note that others have also shown that aPKCs are major activators of NFKB during inflammation and lymphocyte activation (29).

We therefore strongly suspect that aPKC increases BACEl transcription by activating NFKB in hepatocytes and neurons by the following mechanism and linear pathway:

(i) In liver, dietary caloric excesses $\rightarrow$ hepatic aPKC activity $\rightarrow$ IKK $\beta$ activity $\rightarrow$ $\mathrm{NFKB}$ activity $\rightarrow$ BACEl levels $\rightarrow$ IR degradation $\rightarrow$ systemic insulin resistance $\rightarrow$ hyperinsulinemia $\rightarrow$ activation of hepatic spare IRs $\rightarrow$ post-IR hepatic aberrations $\rightarrow$ hyperinsulinemia $\rightarrow$ and so on in a vicious cycle

(ii) and, in brain, hyperinsulinemia, cellular stress/oxidant/inflammatory factors, $\mathrm{A} \beta_{42}$, and so on $\rightarrow$ aPKC activity $\rightarrow$ IKK $\beta$ activity $\rightarrow$ NFkB activity $\rightarrow$ BACEl levels $\rightarrow A \beta$-peptides and $p$-tau, and IR degradation (that is partial and can be bypassed by hyperinsulinemia) $\rightarrow$ AD pathology.

\section{CONCLUSION}

It seems abundantly clear that $\mathrm{AD}$ risk in obesity MetS/T2DM is real, and this risk at least partly results from hyperinsulinemia-induced increases in brain aPKC activity that provokes increases in BACEl levels and production of $A \beta$-peptides and p-tau. Increases in brain aPKC activity and BACEl activity/levels can also proteolytically diminish brain IR levels, but hyperinsulinemia in all mouse and monkey models of obesity/MetS/T2DM that we have examined does not diminish IR-dependent Akt activity; indeed, despite decreases in brain IR levels, brain IR and Akt activities are increased (apparently via "spare" IRs) by hyperinsulinemia and/or other factors.

On the other hand, increases in BACEl activity and levels that occur in nondiabetic $\mathrm{AD}$ can not only increase $\mathrm{A} \beta$-peptide and p-tau levels but presumably can also diminish brain IR levels, and this may diminish insulin-stimulated Akt activation in norm- or hypoinsulinemic subjects. On the other hand, activities of both Akt and aPKC are reportedly elevated by uncertain noninsulin factors in the brains of humans with nondiabetic $\mathrm{AD}$, and this increase in aPKC activity can increase BACEl levels and activity in these AD brains.

Accordingly, there is considerable evidence to suggest that brain aPKC activity is increased in both diabetes-related and nondiabetic forms of LO-AD. And initial findings in mice suggest the feasibility of using chemical aPKC inhibitor treatment to reduce BACE1, A $\beta$-peptides, and p-tau. Alternatively, treatments that target factors that activate aPKCs, or factors that operate between aPKC and BACEl, that is, at levels surrounding NFKB, may also be effective in $A D$ treatment and should be considered. In any event, the continued elucidation of signaling pathways that are operative in $\mathrm{AD}$ pathogenesis is likely to open new avenues for the development of effective treatments for $\mathrm{AD}$. 
Acknowledgments: This work was supported by VA Merit Review Awards, NIDDK RO1 065969-09 (RV Farese), VA Research \& Education Foundation (MP Sajan), NIH (R01 ES016774-01 and R21AG043718), and AHA SFRN 15SFDRN25710468 (M Kindy). Dr. Robert V. Farese is the guarantor of this work, as such, had full access to all the data in the study and takes responsibility for the integrity of the data and the accuracy of the data analysis. This work does not represent the views of the Department of Veteran Affairs or the United States government.

Conflict of Interest: The authors declare no potential conflicts of interest with respect to research, authorship, and/or publication of this chapter.

Copyright and Permission Statement: To the best of our knowledge, the materials included in this chapter do not violate copyright laws. All original sources have been appropriately acknowledged and/or referenced. Where relevant, appropriate permissions have been obtained from the original copyright holder(s).

\section{REFERENCES}

1. Sinha S, Lieberburg I. Cellular mechanisms of $\beta$-amyloid production and secretion. Proc Natl Acad Sci U S A. 1999;96:11049-53. http://dx.doi.org/10.1073/pnas.96.20.11049

2. Nunan J, Small DH. Regulation of APP cleavage by $\alpha-, \beta$ - and $\gamma$-secretases. FEBS Lett. 2000;483:6-10. http://dx.doi.org/10.1016/S0014-5793(00)02076-7

3. Cole SI, Vassar R. The Alzheimer's disease enzyme, BACE1. Mol Degener. 2007;2:70. http://dx.doi. org/10.1186/1750-1326-2-22

4. Kandalepas PC, Vassar R. The normal and pathological roles of the Alzheimer's $\beta$-secretase, BACE1. Curr Alzheimer Res. 2014;11:441-9. http://dx.doi.org/10.2174/1567205011666140604122059

5. Yang L-B, Lindhol K, Yan R, Citron M, Xia W, Yang X-L, et al. Elevated $\beta$-secretase expression and enzymatic activity detected in sporadic Alzheimer's disease. Nat Med. 2003;9:3-4. http://dx.doi. org/10.1038/nm0103-3

6. Liu L, Lauro BM, Ding L, Rovere M, Wolfe MS, Selkoe DJ. Multiple BACEl inhibitors abnormally increase the BACEl protein level in neurons by prolonging its half-life. Alzheimers Dement. 2019;15(9):1183-94. http://dx.doi.org/10.1016/j.jalz.2019.06.3918

7. Hu X, Das B, Hou H, He W, Yan R. BACEl deletion in the adult mouse reverses preformed amyloid deposition and improves cognitive functions. J Exp Med. 2018;215:927-40. http://dx.doi. org/10.1084/jem.20171831

8. Kimura R, Devi L, Ohno M. Partial reduction of BACEl improves synaptic plasticity, recent and remote memories in Alzheimer's disease transgenic mice. J Neurochem. 2010;113:248-61. http:// dx.doi.org/10.1111/j.1471-4159.2010.06608.x

9. Meakin PJ, Mezzapesa A, Benabou E, Haas ME, Bonardo B, Grino M, et al. The beta secretase BACE1 regulates the expression of insulin receptor in the liver. Nat Commun. 2018;9:1306. http://dx.doi. org/10.1038/s41467-018-03755-2

10. Tan J, Evin GG. B-site APP-cleaving enzyme 1 trafficking and Alzheimer's disease pathogenesis. J Neurochem. 2012;120:869-80. http://dx.doi.org/10.1111/j.1471-4159.2011.07623.x

11. Janson J, Laedtke T, Parisi JE, O'Brien P, Peterson RC, Butler PC. Increased risk of type 2 diabetes in Alzheimer's disease. Diabetes. 2004;53:478-81. http://dx.doi.org/10.2337/diabetes.53.2.474

12. Talbot K, Wang Y, Kazi H, Han L-Y, Bakashi KP, Stucky A, et al. Demonstrated brain insulin resistance, IRS-1 dysregulation, and cognitive decline. J Clin Invest. 2012;122:1316-38. http://dx.doi. org/10.1172/JCI59903

13. Sajan MP, Ivey RA, III, Hansen BC, Higgs MG, Kahn CR, Braun U, et al. Atypical PKC, PKC $/ /$ activates $\beta$-secretase and increases $A \beta_{1-40 / 42}$ and phospho-tau in mouse brain and isolated neuronal cells, and 
may link hyperinsulinemia and other aPKC activators to development of pathological and memory abnormalities in Alzheimer's disease. Neurobiol Aging. 2018;43:62-73. http://dx.doi.org/10.1016/j. neurobiolaging.2017.09.001

14. Sajan MP, Hansen BC, Ivey RA, III, Sajan J, Ari A, Song S, et al. Brain insulin signaling is increased in insulin-resistant states and decreases in FoxOs and PGC-l $\alpha$ and increases in $A \beta_{1-40 / 42}$ and phosphotau may abet Alzheimer's development. Diabetes. 2016;65:1892-903. http://dx.doi.org/10.2337/ db $15-1428$

15. Sajan MP, Acevedo-Duncan ME, Standaert ML, Ivey RA, III, Lee MC, Farese RV. Akt-dependent phosphorylation of hepatic FoxOl is compartmentalized on a WD40/Propeller/FYVE scaffold and is selectively inhibited atypical PKC in early phases of diet-induced obesity. A mechanism for impairing gluconeogenic but not lipogenic enzyme expression. Diabetes. 2014;63:2690-701. http://dx.doi. org/10.2337/db13-1863

16. Sajan MP, Nimal S, Mastorides S, Acevedo-Duncan M, Kahn CR, Leitges M, et al. Correction of metabolic abnormalities in a rodent model of obesity, metabolic syndrome and type 2 diabetes by inhibitors of hepatic protein kinase C-iota. Metabolism. 2012;61:459-69. http://dx.doi.org/10.1016/j. metabol.2011.12.008

17. Sajan MP, Ivey RA, III, Lee MC, Farese RV. Hepatic insulin resistance in ob/ob mice involves increases in ceramide, atypical PKC activity and selective impairment of Akt-dependent FoxOl phosphorylation. J Lipid Res. 2015;56:70-80. http://dx.doi.org/10.1194/j1r.M052977

18. Sajan MP, Standaert ML, Nimal S, Varanasi U, Pastoor T, Mastorides S, et al. The critical role of atypical protein kinase C in activating hepatic SREBP-1c and NFKB in obesity. J Lipid Res. 2009;50:1133-45. http://dx.doi.org/10.1194/jlr.M800520-JLR200

19. Craft S. Insulin resistance and Alzheimer's disease pathogenesis: Mechanisms and implications for treatment. Curr Alzheimer Res. 2007;4:147-52. http://dx. doi.org/10.2174/156720507780362137

20. Craft S, Claxton A, Baker LD, Hanson AJ, Cholerton B, Trittschuh EH, et al. Effects of regular and long-acting insulin on cognition and Alzheimer's disease biomarkers: A pilot clinical trial. J Alzheimers Dis. 2017;57:1325-34. http://dx.doi.org/10.3233/JAD-161256

21. Holscher C. First clinical data of the neuroprotective effects of nasal insulin application in patients with Alzheimer's disease. Alzheimers Dementia. 2014;10(Suppl):33-7. http://dx.doi.org/10.1016/j. jalz.2013.12.006

22. Benedict C, Grillo CA. Insulin resistance as a therapeutic target in the treatment of Alzheimer's disease: A state-of-the-art review. Front Neurosci. 2018;12:215-28. http://dx.doi.org/10.3389/ fnins.2018.00215

23. Buxbaum JD, Gandy SE, Cicchetti P, Ehrlich ME, Czernik AJ, Fracasso RP, et al. Processing of Alzheimer beta/A4 amyloid precursor protein: Modulation by agents that regulate protein phosphorylation. Proc Natl Acad Sci U S A. 1990;87:6003-6. http://dx.doi.org/10.1073/pnas.87.15.6003

24. Etcheberrigaray R, Tan M, Dewachter I, Kuipéri C, Van der Auwera I, Wera S, et al. Therapeutic effects of PKC activators in Alzheimer's disease transgenic mice. Proc Natl Acad Sci U S A. 2004;101: 11141-6. http://dx.doi.org/10.1073/pnas.0403921101

25. da Cruz e Silva OA, Rebelo S, Vieira SI, Gandy S, da Cruz e Silva EF, Greengard P. Enhanced generation of Alzheimer's amyloid-beta following chronic exposure to phorbol ester correlates with differential effects on alpha and epsilon isozymes of protein kinase C. J Neurochem. 2009;108:319-30. http:// dx.doi.org/10.1111/j.1471-4159.2008.05770.x

26. Alfonso SI, Callender JA, Hooli B, Antal CE, Mullin K, Sherman MA, et al. Gain-of-function mutations in protein kinase $\mathrm{C} \alpha(\mathrm{PKC} \alpha)$ may promote synaptic defects in Alzheimer's disease. Sci Signal. 2016 May 10;9(427):ra47. http://dx.doi.org/10.1126/scisignal.aaf6209

27. Du Y, Zhao Y, Zhang Q, Tian J, Li Z, Hyang TY, et al. Inhibition of PKC $\delta$ reduces amyloid- $\beta$ levels and reverses Alzheimer disease phenotypes. J Exp Med. 2018;215(6):1665-77. http://dx.doi. org/10.1084/jem.20171193

28. Sajan MP, Farese RV. Insulin signalling in hepatocytes of type 2 diabetic humans. Excessive expression and activity of PKC-ı and dependent processes and reversal by PKC-ı inhibitors. Diabetologia. 2012;55:1446-57. http://dx.doi.org/10.1007/s00125-012-2477-5

29. Diaz-Meco MT, Moscat J. The atypical PKCs in inflammation: NF-kB and beyond. Immunol Rev. 2012;246:154-67. http://dx.doi.org/10.1111/j.1600-065X.2012.01093.x 
30. Anthonsen MW, Andersen S, Solhaug A, Johansen B. Atypical X/PKC conveys 5-lipoxygenase/leucotriene B4-mediated cross-talk between phospholiase $\mathrm{A}_{2} \mathrm{~S}$ regulating NF-kB activation in response to tumor necrosis factor- $\alpha$ and interleukin-1 $\beta$. J Biol Chem. 2001;276:35344-51. http://dx.doi. org/10.1074/jbc.M105264200

31. Kyali AG, Austin JA, Webster NJG. Rottlerin inhibits insulin-stimulated glucose transport in 3T3/L1 adipocytes by uncoupling mitochondrial oxidative phosphorylation. Endocrinology. 2009;143:388498. http://dx.doi.org/10.1210/en.2002-220259

32. Vancurova A, Miskoloci V, Davidson D. NF kappa B activation in tumor necrosis factor-alpha-stimulated neutrophils is mediated by protein kinase Cdelta. Correlation to nuclear IkappaBalpha. J Biol Chem. 2001;276:19746-52. http://dx.doi.org/10.1074/jbc.M100234200

33. Ciccocioppo F, Lanuti P, Marchisio M, Gambi F, Santavenere E, Pierdomenico L, et al. Expression and phosphorylation of protein kinase isoforms in $A \beta_{1-42}$ activated $T$ lymphocytes from Alzheimer disease. Int J Immunopathol Pharmacol. 2008;21:23-33. http://dx.doi. org/10.1177/039463200802100104

34. Miscia S, Ciccocioppo F, Lanuti P, Velluto L, Bascelli A, Pierdomenico L, et al. Abeta(1-42) stimulated T cells express PKC-delta and PKC-zeta/lambda/iota in Alzheimer disease. Neurobiol Aging. 2009;330:394-406. http://dx.doi.org/10.1016/j.neurobiolaging.2007.07.011

35. Sajan MP, Ivey RA, III, Farese RV. Metformin action in human hepatocytes. Co-activation of atypical protein kinase C alters 5'-AMP-activated protein kinase effects on lipogenic and gluconeogenic enzyme expression. Diabetologia. 2013;56:2507-3010. http://dx.doi.org/10.1007/s00125-013-3010-1

36. Sajan MP, Ivey RA, III, Lee MC, Mastorides S, Jurzak MJ, Samuels VT, et al. PKC入 haplo-insufficiency prevents diabetes by a mechanism involving alterations in hepatic enzymes. Mol Endocrinol. 2014;28:1097-107. http://dx.doi.org/10.1210/me.2014-1025

37. Sajan MP, Standaert ML, Rivas J, Miura A, Kanoh Y, Soto J, et al. Role of atypical protein kinase C in activation of sterol regulatory element binding protein-lc and nuclear factor kappa B (NFKB) in liver of rodents used as model of diabetes, and relationships to hyperlipidaemia and insulin resistance. Diabetologia. 2009;52:1197-207. http://dx.doi.org/10.1007/s00125-009-1336-5

38. Apostolatos AH, Apostolatos CA, Ratnayake WS, Neuger A, Sansil S, Bourgeois M, et al. Preclinical testing of 5-amino-1-((1R,2S,3S,4R)-2,3-dihydroxy-4-methylcyclopentyl)-1H-imidazole-4-carboxamide: A potent protein kinase C-t inhibitor as a potential prostate carcinoma therapeutic. Anticancer Drugs. 2019;30:65-71. http://dx.doi.org/10.1097/CAD.0000000000000694

39. Sacktor TC. PKMzeta, LTP maintenance, and the dynamic molecular biology of memory storage. Prog Brain Res. 2008;169:27-40. http://dx.doi.org/10.1016/S0079-6123(07)00002-7

40. Tsokas P, Hsieh C, Yao Y, Lesburgueres E, Wallace EJC, Tcherepanov A, et al. Compensation for PKM in LTP and spatial long-term memory in mutant mice. eLife Sci. 2016;5:el4846. http://dx.doi. org/10.7554/eLife. 14846

41. Sheng T, Wang S, Qian D, Gao J, Ohno S, Lu W. Learning-induced suboptimal compensation for PKCI $\lambda$ function in mutant mice. Cerebral Cortex. 2017;27:3284-93. http://dx.doi.org/10.1093/ cercor/bhx077

42. Wang S, Sheng T, Ren S, Tian T, Lu W. Distinct roles of PKCI $\lambda$ and PKM $\zeta$ in the initiation and maintenance of hippocampal long-term potentiation and memory. Cell Rep. 2018;16:1954-61. http:// dx.doi.org/10.1016/j.celrep.2016.07.030

43. Miranda C, Miele GA, Pierotti MA, Van Obberghen E. IRS-1 and IRS-2 are recruited by TrkA receptor and oncogenic TRK-T1. J Cell Physiol. 2001;186:35-46. http://dx.doi.org/10.1002/ 1097-4652(200101)186:1\%3C35::AID-JCP1003\%3E3.0.CO;2-X

44. Woolen MW, Selbenhener ML, Neidigh KB, Vandanplas ML. Mapping of atypical protein kinase C within the nerve growth factor signaling cascade: Relationship to differentiation and survival of PC12 cells. Mol Cell Biol. 2000;20:4494-504. http://dx.doi.org/10.1128/MCB.20.13.4494-4504.2000

45. Melemedjian OK, Tillu DV, Asiedu MN, Mandell EK, Moy JK, Blute VM, et al. BDNF regulates atypical PKC at spinal synapses to initiate and maintain centralized chronic pain state. Molec Pain. 2013;9: 12-26. http://dx.doi.org/10.1186/1744-8069-9-12

46. Brennan-Minnella AM, Shen Y, Swanson RA. Phosphoinositide 3-kinase couples NMDA receptors to superoxide release in excitotoxic neuronal death. Cell Death Dis. 2013;4:e580. http://dx.doi. org/10.1038/cddis.2013.111 
47. Koponen S, Kurkinen K, Akerman KE, Mochly-Rosen D, Chan PH, Koistinaho J. Prevention of NMDA-induced death of cortical neurons by inhibition of protein kinase Czeta. J Neurochem. 2003;86:442-50. http://dx.doi.org/10.1046/j.1471-4159.2003.01846.x

48. Ivey RA, Sajan MP, Farese RV. Pseudosubstrate arginine residues are required for auto-inhibition and are targeted by phosphatidylinositol-3.4.5- $\left(\mathrm{PO}_{4}\right)_{3}$ during aPKC activation. J Biol Chem. 2014;289:25021-30. http://dx.doi.org/10.1074/jbc.M114.565671

49. Sajan MP, Bandyopadhyay G, Kanoh Y, Standaert ML, Quon MJ, Reed BC, et al. Sorbitol activates atypical protein kinase C and GLUT4 glucose transporter translocation/glucose transport through proline-rich tyrosine kinase-2, the extracellular signal-regulated kinase pathway and phospholipase D. Biochem J. 2002;362:665-74. http://dx.doi.org/10.1042/bj3620665

50. Bandyopadhyay G, Sajan MP, Kanoh Y, Standaert ML, Quon MJ, Reed BC, et al. Glucose activates protein kinase $\mathrm{C}-\mathrm{z} / \mathrm{l}$ through proline-rich tyrosine kinase-2, extracellular signal-regulated kinase, and phospholipase D. A novel mechanism for activating glucose transporter translocation. J Biol Chem. 2001;276:35537-45. http://dx.doi.org/10.1074/jbc.M106042200

51. Thaler JP, Choi SJ, Sajan MP, Ogimoto K, Nguyen HT, Matsen M, et al. Atypical protein kinase C activity in the hypothalamus is required for lipopolysaccharide-mediated sickness responses. Endocrinol. 2009;150:5362-72. http://dx.doi.org/10.1210/en.2009-0509

52. Buggia-Prevot V, Sevalle J, Rossner S, Checler F. NFkB-dependent control of BACEl promoter transactivation by Ab42. J Biol Chem. 2008;283:10037-47. http://dx.doi.org/10.1074/jbc.M706579200

53. Chen C-H, Zhou W, Liu S, Deng Y, Cai F, Tone M, et al. Increased NF-k-B signaling up-regulates BACEl expression and its therapeutic potential in Alzheimer's disease. Int J Neuropsychopharmacol. 2012;15:77-90. http://dx.doi.org/10.1017/S1461145711000149

54. Wang R, Chen S, Liu Y, Diao S, Xue Y, You X, et al. All-trans-retinoic acid reduces BACEl expression under inflammatory conditions via modulation pf nuclear factor kB (NFkB) signaling. J Biol Chem. 2015;290:22532-42. http://dx.doi.org/10.1074/jbc.M115.662908 